\title{
O que vês? / O que lês?: imagináveis aproximações entre Fílon e Zacarias
}

Cesar Motta Rios

FALE-UFMG

profecesarmr@yahoo.com.br

ABSTRACT: In this note, I propose a discussion based on the possibility of comparison between the Philo of Alexandria's allegorical interpretation, and the one used in Zechariah's book. By using selected examples, in which I have found similarities and dissimilarities between both authors, I aim to demonstrate that the semiotic difference of the object read in the prophet's text must be taken into account when compared to Philo's "textual" allegorical interpretation. At the end, I try to expose a reflection on the tradition of allegorical readers (or readings) and the place of Zechariah's text in it.

KEYWORDS: Philo of Alexandria; Zechariah (the prophet); Jewish hermeneutic; allegory.

\section{Início da conversa: Fílon cita Zacarias}

Relacionar Fílon com Zacarias não é uma tarefa de todo insólita. A aproximação poderia ser sugerida, em princípio, pela leitura de um trecho de certo tratado filônico, Sobre a confusão das línguas, no qual o hermeneuta cita um texto do profeta como exemplo.

O trecho em questão pode revelar algum detalhe interessante para a presente reflexão, por isso, trato de examiná-lo com algum cuidado. Em Conf. 60, Fílon cita Gn. $11: 2^{1}$ e diz que o texto é dito "muito naturalmente" ( $\phi v \sigma ı \kappa \omega ́ \tau \alpha \tau \alpha-$ physikótata), ou melhor, considerando a especificidade do termo quando utilizado por Fílon, ${ }^{2}$ "de modo que muito expressa a natureza das coisas". Com o termo, o intérprete já anuncia que introduzirá uma leitura alegórica. É o que faz ao dizer em seguida que "Oriente" ( $\dot{\alpha} \nu \alpha \tau \circ \lambda \hat{\eta} \varsigma$ - anatolês) tem dois aspectos ( $(\hat{i} \delta \circ \varsigma$ - eídos) quando se refere à alma, a saber, o melhor ( $\tau \grave{\text { ò } \alpha ́ \mu \varepsilon \imath v o v ~-~ a ́ m e i n o n) ~ e ~ o ~ p i o r ~(\tau o ̀ ~ \chi \varepsilon i ̂ p o v ~-~ t o ̀ ~ k h e i ̂ r o n) . ~ A ~ s e g u i r, ~}$ evoca $G n .2: 8^{3}$ como uma primeira prova. O texto diz que Deus plantou um Jardim no Édem, no Oriente. Obviamente, para Fílon, não pode tratar-se de um jardim de plantas terrenas, mas de virtudes celestiais. Em seguida, buscando mais um respaldo, Zacarias é convocado ao texto nos seguintes termos:

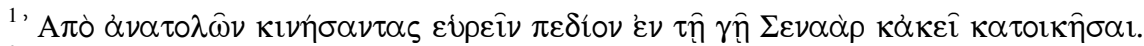

${ }^{2}$ Cf. Rios, C. M. A alegoria na tessitura de Fílon de Alexandria. Estudo a partir da obra filônica com ênfase em Sobre os "Sonhos I". Belo Horizonte: FALE-UFMG, 2009, p. 91-92 (dissertação de mestrado em estudos clássicos); Najman, I. A written copy of the law of nature. An unthinkable paradox? Studia philonica annual. Vol. XV, p. 54-63, 2003; Nikiprowetzky, V. L'exégèse de Philon d'Alexandrie. Revue d'histoire et de philosophie religieuses. Paris, p. 324, 1973.

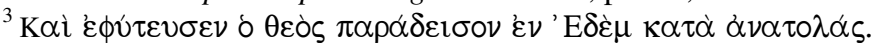




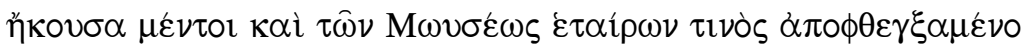

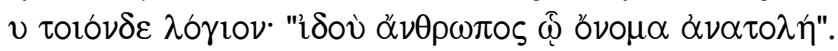

Eu ouvi, certamente, também um dos companheiros de Moisés que declarava com clareza o seguinte oráculo: "Eis um homem cujo nome é Oriente". ${ }^{4}$

Dois detalhes me parecem especialmente notáveis nessa frase. O primeiro é a maneira como Fílon caracteriza Zacarias: "Um dos companheiros de Moisés". Decerto, não se trata de um elogio desprezível, uma vez que Moisés recebe um apreço muito elevado por parte do hermeneuta. ${ }^{5}$ Mas uma ou duas perguntas podem ser levantadas: o que faz de Zacarias um companheiro de Moisés é somente o fato de ser profeta? E, sendo livre em minha leitura, penso: Seria possível pensar em Zacarias como um companheiro também de Fílon em algum sentido? Em que sentido?

Essas questões devem ser repensadas em breve. Antes, outro detalhe deve ser observado: o que leva o hermeneuta a citar Zacarias quando fala de um trecho do Gênesis? A meu ver, o que gera a possibilidade da relação entre os textos é

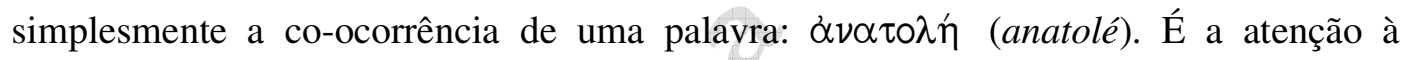
palavra escrita e lida que possibilita a Fílon enveredar-se pelo texto do profeta. Esse fato também deve ser lembrado, pois marca a principal diferença que percebo entre a interpretação de Fílon e muitas outras.

\section{Um Zacarias alegorista}

Outra forma de se aproximar Zacarias e Fílon é indiretamente possibilitada por Klaus Berger. ${ }^{6}$ Em seu livro As formas literárias do Novo Testamento, Berger dedica um tópico aos chamados "textos analógicos e figurativos", dentre os quais ele apresenta “alegoria e alegorese”. Sua concepção de alegoria depende profundamente da categoria "imagem", o que se nota nas seguintes frases:

O conceito de alegoria usado na ciência da literatura, significa determinado modus de dois textos se relacionarem entre si. Em

\footnotetext{
${ }^{4}$ Cf. Zacarias 6:12 (minha tradução).

${ }^{5} \mathrm{O}$ verso que Fílon cita de Zacarias é uma fala atribuída a Deus, mas julgo improvável que ele chame o Eterno de "um dos companheiros de Moisés", por isso, considero certo que ele esteja falando do profeta nesses termos.

${ }^{6} \mathrm{O}$ fato me foi levantado pela profa. Dra. Tereza Virgínia Barbosa Ribeiro (FALE-UFMG). Por isso, considero esta nota como a continuação de um diálogo que com ela comecei em 04/ 02/ 2009.
} 
primeiro lugar, é essencial a sequência destes textos. Na frente está um texto que depois é interpretado como constituindo o "plano da imagem". Segue um texto explicativo que no "plano de partida", da linguagem normal, descreve o significado da imagem. ${ }^{7}$

Essa concepção é compartilhada por outros que pensaram sobre a alegoria, inclusive por filonistas. Assim declara, por exemplo, Émile Bréhier: "Ela [a alegoria] consiste essencialmente em determinar uma ideia por uma imagem.",

Coerente com essa concepção, Berger apresenta, entre outros exemplos, um tipo de alegoria que consiste em um diálogo entre o revelador (o intérprete) e o receptor da “imagem”. Então, afirma:

A forma mais antiga desse gênero encontrada até hoje é a visão com diálogo de Zc. 4-6. O anjo incentiva a contemplar a visão (p.ex., 5,5) e pode em seguida fazer perguntas como: "Tu não sabes o que isso significa?", ao que o vidente responde: "Não, meu senhor" $(4,13)$. Aí surge a explicação por meio da identificação (...é...), típica também de todos os textos posteriores. ${ }^{9}$

Nesse caso, somos levados a considerar Zacarias como produtor de uma espécie de "proto-alegoria", ou "alegoria primitiva". A relação entre as visões do profeta e o termo "alegoria", na verdade, não é nova. No final do século XIX, já se lia, com respeito às visões de Zacarias, em um volume sobre os doze profetas: "O que temos não é a narração de verdadeiros sonhos, mas uma série de alegorias conscientes e artísticas". ${ }^{10}$

Se assim é, Fílon e Zacarias seriam também aproximados por compartilharem um modo de leitura semelhante. A meu ver essas conclusões não devem ser tomadas apressadamente. Observemos rapidamente, então, o que cada um realmente faz.

\section{Visão-Interpretação em Zacarias/ Texto-Interpretação em Fílon}

Como exemplo da interpretação apresentada no livro do profeta, abordo a visão relatada em $Z c$. 4:1-14. O texto se inicia com o narrador dizendo ter sido despertado

\footnotetext{
${ }^{7}$ Cf. Berger, K. As formas literárias do Novo Testamento. Tradução de Fredericus Antonius Stein. São Paulo: Loyola, 1998, p. 58.

${ }^{8}$ Cf. Bréhier, op. cit., p. 35 (minha tradução).

${ }^{9}$ Cf. Berger, op. cit., 1998, p. 59.

${ }^{10}$ Cf. Smith, apud Haupt, P. The Visions of Zechariah. Journal of biblical literature. Atlanta, vol. XXXII, n. 2, p. 108, 1913 (minha tradução).
} 
pelo anjo que com ele conversava. Em seguida, o anjo (הַפְְלִ - haMálakh) ${ }^{11}$ lhe

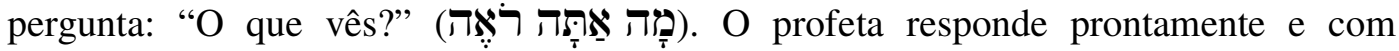
detalhes à pergunta. Ele vê um lampadário e duas oliveiras. Após descrever a visão, pede ao anjo que diga o que são tais coisas. $\mathrm{O}$ anjo lhe pergunta se não sabe o que são

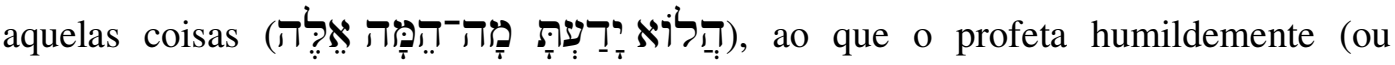

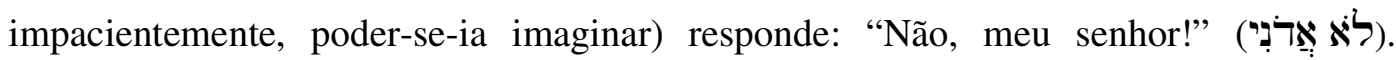
Então, segue a explicação do anjo com respeito ao lampadário. O profeta toma a palavra e pergunta especificamente sobre as oliveiras. $\mathrm{O}$ anjo volta a perguntar se ele não sabe o que são e ele repete: "Não, meu senhor!".

O profeta mostra-se na dependência do anjo-hermeneuta. Sem sua ajuda, a visão seria ininteligível, o que é enfatizado pela insistência do anjo em perguntar se ele não sabe o que são aquelas coisas. Há, portanto, não só uma submissão ao, mas inclusive uma veneração do anjo por parte do profeta. Este o chama de "meu senhor". Mas uma pergunta específica me chama a atenção: “O que vês?”. Esta, que é a primeira pergunta do anjo, é bem razoável, já que o profeta é, sobretudo, um vidente e o que ele precisa traduzir, tornar compreensível, nada mais é que uma visão, uma imagem.

E no caso de Fílon? Claro, ele poderia decerto ser comparado ao anjohermeneuta de Zacarias. Mas o que ele procura explicar não são imagens, mas um texto. Claro, talvez Berger e Bréhier entenderiam que o que ele traduz são as imagens narradas na Torah. Ou seja, as imagens evocadas pelas palavras do texto seriam lidas alegoricamente como apresentando outro sentido que não o das imagens mesmas. Razoável a afirmação, mas a julgo insustentável no caso de Fílon. Acontece que o alexandrino é homem de leitura, de atenção às palavras. Seu trato é com o texto enquanto tal. É por esse caminho, lembre-se, que ele chega a citar o próprio Zacarias!

É notável, por exemplo, que mesmo quando o texto da Torah parece solicitar uma interpretação preponderantemente imagética, Fílon se atém às palavras. Em Sobre os Sonhos I, ao interpretar o sonho de Jacó com a escada entre céu e terra, o alexandrino não se detém nas imagens somente, mas sim atenta para a seguinte fala do Ser que está sobre a escada: "Eu sou o Senhor, Deus de teu pai Abraão e Deus de Isaque. Não

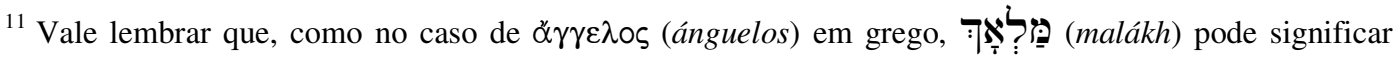
anjo, mas seu sentido original é simplesmente o de mensageiro. Enquanto em Zacarias o anjo é anônimo, em Daniel, texto posterior, será Gabriel o encarregado de explicar a visão ao que, sem sua ajuda, era incapaz de resolvê-la (Dn. 8).
} 
temas". ${ }^{12}$ Então, em certo momento, diz:

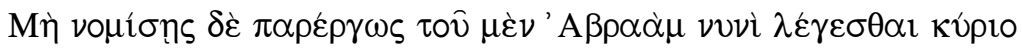

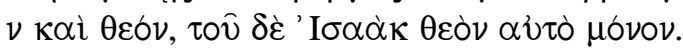

E que não julgues ser dito de modo incidental nesse trecho "Senhor e Deus" de Abraão, enquanto somente "Deus" de Isaque. ${ }^{13}$

E, a partir deste detalhe encontrado em uma fala do sonho relatado (não em uma imagem), Fílon tece uma interpretação alegórica complexa, que ocupa considerável parte do texto subsequente.

Também se deve lembrar que a etimologia é um recurso muito utilizado por Fílon na apresentação de suas interpretações alegóricas, o que é impossível quando o interpretado é uma imagem e não um texto. Isso é vital para que se compreenda a natureza do trabalho exegético de Fílon. Para ele, o sentido histórico da Torah pode ser verdadeiro (realmente houve um homem chamado Abraão, o qual deixou a casa dos seus etc), mas não somente esse enredo histórico é importante, também a maneira como Moisés o escreveu deve ser interpretada. O histórico pode ser considerado a maneira como Deus criou (poderiamos utilizar o verbo grego e dizer "a maneira como Deus

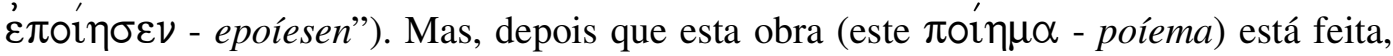
aparece o primeiro mediador, Moisés, responsável por relatá-la em texto, levá-la ao verbal. Agora, Fílon trata com esse texto verbal e não busca apenas na imagem do narrado (a imagem-significada), mas na própria narração (a palavra-significante), a emergência do outro sentido. Sua crença na importância da tessitura de Moisés fica clara nas seguintes palavras:

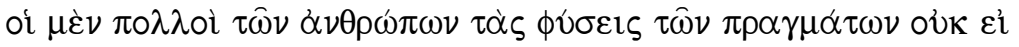

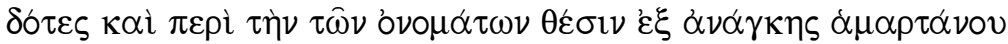

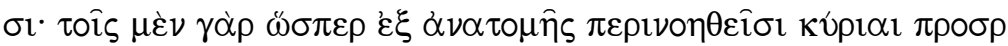

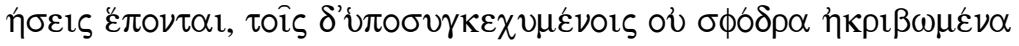

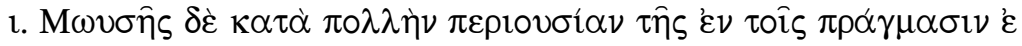

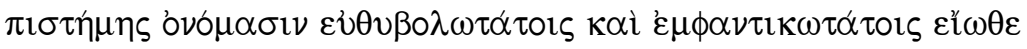

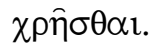

Muitos dos seres humanos, não conhecendo as naturezas das coisas, necessariamente também erram no que diz respeito à colocação dos nomes. Pois a umas coisas, consideradas a partir de um

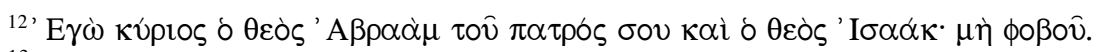

${ }^{13}$ Cf. Sobre os Sonhos I 160. 
seccionamento, se unem designações próprias, a outras, que permanecem confusas, designações não muito rigorosamente pensadas. Mas Moisés, segundo a grande abundância de ciência para com as coisas, costuma lançar mão dos mais certeiros e claros nomes. ${ }^{14}$

Muitos outros trechos da obra de Fílon poderiam ser evocados para demonstrar como ele confia em uma seleção vocabular meticulosa por parte do escritor do texto sagrado. Seleciono, contudo, apenas um, para não ser enfadonho. Em Sobre a criação do mundo, Fílon diz que a serpente do Éden, a que tentou Eva, significa alegoricamente o "amante do prazer". Após demonstrar a procedência analógica da relação, evoca como respaldo de sua interpretação um animal que lhe seja oposto: um tipo de locustídio

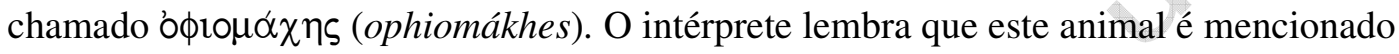
em Levítico 11:22, constando entre os insetos que podem ser comidos. O fato de ser liberado para o consumo favorece a contraposição de Fílon, instigada precisamente pelo

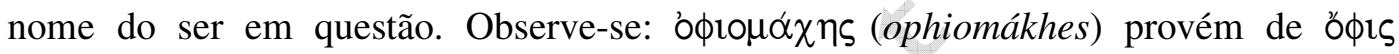
(óphis), "serpente", e $\mu \alpha ́ \chi \eta \varsigma$ (mákhes), "combate". Claro, além disso, o inseto costuma saltar, dirigir-se ao alto, diferente da cobra que caminha sobre o ventre junto ao chão.

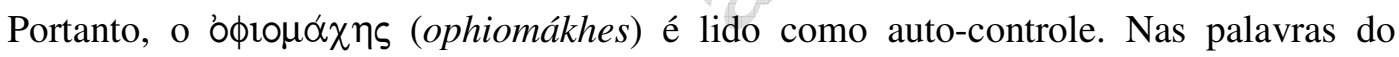
alexandrino: "Pois o ophiomákhes não me parece ser nada mais que o autocontrole simbolicamente". ${ }^{15} \mathrm{O}$ procedimento de Fílon revela, além de uma crença na unidade do texto sagrado, uma leitura feita não somente a partir das imagens, dos significados, mas também (e de modo imprescindível neste e em outros casos) da palavra, dos significantes.

Sem dúvida, a concepção que Fílon tinha de alegoria, inclusive por uma característica elementar de seu objeto de interpretação, transcendia em muito a ideia de interpretação de uma imagem. O fato já parece claro. Portanto, ele, no lugar do anjohermeneuta, não perguntaria de início a seu interlocutor "

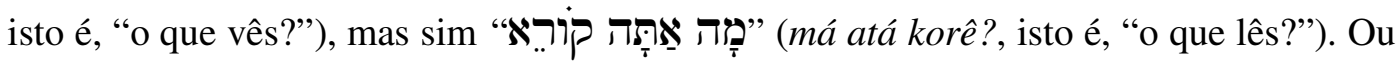

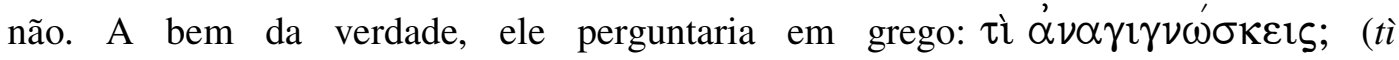
anaguignóskeis?).

E por ele perguntar em grego, cabe apresentar ao menos uma definição grega de

\footnotetext{
${ }^{14} \mathrm{Cf}$. Sobre a agricultura $1-2$.

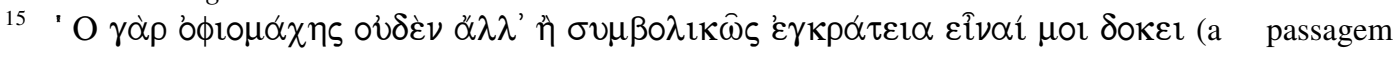
citada se encontra aqui em minha tradução).
} 
alegoria. Cocôndrio, autor de data incerta, a afirma nos seguintes termos:

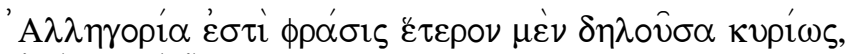

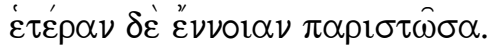

Alegoria é frase que declara uma coisa propriamente, mas assenta outra intelecção. ${ }^{16}$

Além de marcar o fato de que, na alegoria, não há supressão de um sentido (o próprio, literal) pelo outro (o alegórico), ambos provenientes da mesma enunciação, a

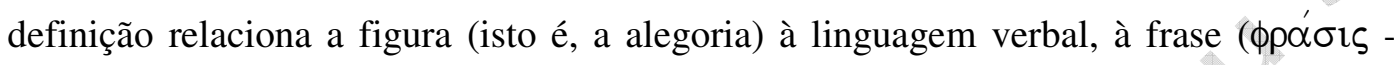
phrásis).

Ademais, lembro o fato de que a interpretação alegórica de Fílon, concorde com essa e outras definições gregas, pode ser muito bem comparada, no meu entender, àquela praticada entre os intérpretes gregos. Alguns de seus procedimentos são muito semelhantes, por exemplo, aos encontrados em Alegorias de Homero, texto de um certo Heráclito (provavelmente, séc. I d.C.,). Talvez isso se dê devido ao caráter do objeto interpretado. Ambos, Heráclito e Fílon se deparam com textos, linguagem verbal.

E a quê se compararia a interpretação de Zacarias? No mundo grego, um documento comparável é a Tábua de Cebes, tratado de autoria e datação duvidosas. Nesse documento, narra-se o diálogo entre duas pessoas. Uma contempla um painel, enquanto outra lhe explica os significados de cada parte da imagem. De modo rápido, então, eu diria que Alegorias de Homero está para a Tábua de Cebes como Fílon para Zacarias. Há semelhanças, mas também uma considerável diferença.

A não observação dessa diferença, contudo, faz com que Bréhier pense que a Tábua de Cebes apresenta o tipo de interpretação que mais se aproxima àquela praticada por Fílon. ${ }^{17}$ Claro, em sua própria definição de alegoria, o erudito francês demonstrava, como vimos, uma atenção especial à imagem, embora estudasse o caso de Fílon. Percebo nisso um desacerto.

\title{
4. Uma família de alegoristas
}

Após essas rápidas observações, volto ao problema que motiva esta nota: saber que relação pode ser pensada entre a hermenêutica de Fílon e os diálogos de Zacarias

\footnotetext{
${ }^{16}$ Cf. dos Santos, M. M. Lições de alegoria de gramáticos e retores gregos e latinos. São Paulo: FFLCHUSP, 2002, p. 173 (tese de doutorado em letras clássicas).

${ }^{17}$ Cf. Bréhier, op. cit., p. 41-43.
} 
com o anjo-hermeneuta.

De início, deve-se notar que há uma diferença considerável entre os trabalhos dos dois, embora alguma semelhança também seja perceptível. Curiosamente, em algum momento, é possível pensar que o texto do profeta se assemelha mais ao encontrado na Tábua de Cebes. Os dois cuidam de explicar imagens. Então, os tratados de Fílon seriam melhor comparados à obra de Heráclito. Isso, considerando-se a natureza do objeto da interpretação, não a origem étnica dos escritores.

Por outro lado, Zacarias é trazido a esta discussão e às comparações estabelecidas porque o judeu Fílon de Alexandria consagrou a alegorese, com procedimentos semelhantes aos utilizados por intérpretes gregos, como um modo de se ler a Torah e, assim, revelar um sentido oculto da mensagem sagrada. Ele aproximou um método preponderantemente grego a um objeto estritamente judaico (ou nem tão estritamente, já que se tratava de uma tradução ao grego). Assim, ele possibilitou e até instigou olhares simultaneamente direcionados aos dois arquivos com os quais trabalhava: o grego e o judaico. E, por isso, Zacarias pode ser posto ao lado da Tábua de Cebes.

Burke Long observa que as visões de Zacarias mais parecem artifícios literários e sugere que, uma vez que os diálogos entre anjo e profeta no livro de Zacarias objetivam uma interpretação que decifre mistérios divinos ou experiências humanas a partir do visto, sua linguagem "tende para a alegoria". ${ }^{18}$ A ideia, já cuidadosa em sua formulação, poderia ser assim repensada: a linguagem do diálogo se assemelha a uma certa maneira de se interpretar textos que, praticada entre os gregos, veio a se chamar alegoria pouco antes da era Cristã. Ou seja, o termo alegoria e seus correlatos só são atribuídos à linguagem de Zacarias por uma leitura retroativa, que considera as tradições alegoristas que se desenvolveram séculos após a morte do profeta.

Zacarias influenciou Fílon? A meu ver, ele, no máximo, corrobora com o trabalho exegético do alexandrino ao apresentar, dentro do cânon sagrado judaico, sendo contado como "companheiro de Moisés", um tipo de interpretação que vai além do sentido mais óbvio, imediato, literal (O mesmo fazem as parábolas de Ezequiel, por exemplo.). A necessidade dessa corroboração, contudo, é difícil de comprovar, uma vez que Fílon mesmo não se preocupa em justificar seus métodos com base em exemplos assim.

\footnotetext{
${ }^{18}$ Cf. Long, B. O. Reports of Visions among the prophets. In: Journal of biblical literature. Atlanta, vol. XCV, n. 3, p. 363, 1976).
} 
Para se pensar a relação entre o intérprete judeu-alexandrino, talvez fosse útil que não nos ativéssemos às ideias simples e desgastadas de fonte, influência, débito e crédito. Um pensamento como o exposto por Borges em seu pequeno ensaio Kafka y sus precursores $^{19}$ parece-me proveitoso por levar-me a conjecturar sobre o Fílon que cria Zacarias como seu precursor. Entenda-se: não fosse a obra filônica, para mim, Zacarias não figuraria ao lado da Tábua de Cebes ou de Heráclito, mas somente junto a Amós, Ezequiel, Habacuque etc. É o alexandrino quem adentra na história da interpretação alegórica (grega), trazendo debaixo do braço um rolo novo, no qual está a Lei dos judeus traduzida ao grego. Ele é quem se coloca à mesa, junto aos gregos, em um diálogo consistente e duradouro, e convida, mesmo que sem se aperceber, outros tantos textos judaicos a participar dessa família. $\mathrm{O}$ alexandrino mistura os arquivos (por ser ele mesmo um "misturado"), ainda que preserve uma clara etiqueta sobre os cinco livros de Moisés, diferenciando-os dos demais: é a Lei. Assim, não é Zacarias quem possibilita a Fílon o ser alegorista, mas Fílon quem pode fazer de Zacarias (quer direta ou indiretamente) um protoalegorista.

\section{Observações finais}

Devo observar, ainda, que o interessante na lida com todos esses intérpretes é que o interpretado não é tanto o centro das atenções, mas o próprio interpretar. Todos eles testemunham um anseio de querer pensar, entender, envolver-se com o que leem/veem, como crendo que ali se tivesse escondido algo de muito valor. Por isso, seus textos, quer tenham gerado ou não uma tradição concorde nas épocas posteriores, registram um esforço, uma atenção, um comprometimento e (por que não dizer com todos os possíveis sentidos da palavra?) uma paixão. Tudo isso, faz dessa uma família instigante e é isso o que, no fim das contas, os une.

Para terminar, assinalo minha convicção de que pesquisas comparatistas nesse campo podem ser muito produtivas. A comparação da hermenêutica de Fílon com outras formas de interpretação judaica, por exemplo, será proveitosa desde que não se queira definir relações hierarquizadas entre os textos de épocas e canonicidades diferentes, nem se desconsidere as especificidades de cada obra. Observadas tais ressalvas, inclusive a comparação com Zacarias e outros profetas da Tanakh pode ser válida. Um possível estudo relacionaria os diálogos entre o profeta e o anjo-hermeneuta

${ }^{19}$ Cf. Borges, J. L. Kafka y sus precursores. In: Obras completas. Buenos Aires: Emecé Editores, 1974. Vol. II, p. 88-90. 
com o que chamo de negociação do sentido alegórico, momentos em que o alexandrino tece, ao longo de seus tratados, uma negociação retórica em prol do sentido alegórico proposto para um ou mais itens do texto. ${ }^{20}$ Ademais, é notável o fato de que, semelhante ao profeta, Fílon também indica que tem, por vezes, uma mediação mística em suas interpretações. ${ }^{21}$ É urgente, ainda, entender melhor o lugar de Fílon entre outras obras do judaísmo de língua grega, bem como a maneira como ele e esse ramo do judaísmo em geral lidam com o encontro dessas duas culturas de letras e livros. Para tanto, as comparações não estão por acabar-se.

\section{Referências}

BERGER, K. As formas literárias do Novo Testamento. Tradução de Fredericus Antonius Stein. São Paulo: Loyola, 1998.

BORGES, J. L. Kafka y sus precursores. In: Obras completas. Buenos Aires: Emecé Editores, 1974. Vol. II, p. 88-90.

BRÉHIER, É. Les idées philosophiques et religieuses de Philon d'Alexandrie. Paris: Librairie Philosophique J. Vrin, 1950.

HAUPT, P. The visions of Zechariah. Journal of biblical literature. Atlanta, vol. XXXII, n. 2, p. 107-122, 1913.

LONG, B. O. Reports of visions among the prophets. Journal of biblical literature. Atlanta, vol. XCIII, n. 3, p. 353-365, 1976.

NAJMAN, I. A written copy of the law of nature. An unthinkable paradox? Studia philonica annual. Vol. XV, p. 54-63, 2003.

NIKIPROWETZKY, V. L'exégèse de Philon d'Alexandrie. Revue d'histoire et de philosophie religieuses. Paris, 1973.

RIOS, C. M. A alegoria na tessitura de Fílon de Alexandria. Estudo a partir da obra filônica com ênfase em "Sobre os Sonhos I". Belo Horizonte: FALE-UFMG, 2009 (dissertação de mestrado em estudos clássicos).

\footnotetext{
${ }^{20}$ Claro, neste caso, outros textos poderiam ser igualmente pertinentes para uma reflexão comparatista: diálogos semelhantes aos de Zacarias entre outros profetas e Deus, bem como algumas conversas relatadas nos Evangelhos, nas quais Jesus explica o sentido de parábolas a seus discípulos.

${ }^{21}$ Cf. Sobre o Querubim 27.
} 


\section{nuntius antiquus}

dos SANTOS, M. M. Lições de alegoria de gramáticos e retores gregos e latinos. São Paulo: FFLCH-USP, 2002 (tese de doutorado em letras clássicas). 